\title{
INFLUÊNCIA DA UTILIZAÇÃO DO REGULADOR DE CRESCIMENTO EM DIFERENTES DENSIDADES DE SEMEADURA NA CULTURA DO ARROZ DE TERRAS ALTAS NA REGIÃO DE FERNANDÓPOLIS - SP.
}

\author{
SILVA, Marcelo Romero Ramos da ${ }^{1}$ \\ RODRIGUES, Ricardo Antônio Ferreira ${ }^{2}$ \\ ARF, Orivaldo ${ }^{3}$
}

RESUMO: O objetivo do trabalho foi avaliar a influência do regulador de crescimento etil-trinexapac em diferentes densidades de semeadura do arroz de terras altas, cultivar BRS Primavera, no município de Fernandópolis - SP, visando reduzir a altura e diminuir o acamamento das plantas. O experimento foi conduzido na Fazenda de Ensino e Pesquisa da Universidade Camilo Castelo Branco, Campus de Fernandópolis - SP. O delineamento experimental utilizado foi blocos ao acaso, disposto em esquema fatorial $5 \times 2$, com quatro repetições. Os tratamentos foram constituídos por cinco densidades de semeadura (100, 150, 200, 250 e 300 sementes viáveis $/ \mathrm{m}^{2}$ ), com e sem aplicação de regulador de crescimento. A utilização do regulador de crescimento constitui uma ferramenta importante, mas que ainda influencia nos componentes vegetativos, produtividade e ainda interfere no rendimento industrial do cultivar BRS Primavera .

Palavras-chave: Oryza sativa L.. População de plantas. Retardante vegetal. Componentes de produção.

\section{INFLUENCE OF THE USE OF GROWTH REGULATOR UNDER DIFFERENT SOWING DENSITIES IN THE CULTURE OF UPLAND RICE CROP IN FERNANDÓPOLIS - SP.}

\begin{abstract}
SUMMARY: The objective of this research was to study the influence of growth regulators ethyl-trinexapac on sowing densities on upland rice, growing BRS Primavera, in Fernandópolis - SP, aiming to reduce plant height and to prevent possible lodging of the rice plants. The experiment started on the Experimental Farm of Camilo Castelo Branco University, Campus of Fernandópolis, SP. The experimental design used was randomized blocks with treatments in factorial arrangement $5 \times 2$. There were four repetitions. The treatments were made of five combination of sowing densities $\left(100,150,200,250\right.$ and 300 seeds $\left./ \mathrm{m}^{2}\right)$, with and without the use of growth regulator ethyl-trinexapac. The use of growth regulators is an important tool in the management of upland rice culture, but it still influences the vegetative components and productivity, and it interfere with the performance of industrial BRS Primavera.
\end{abstract}

Keywords: Oryza sativa L.. Plant population. Retardant plant. Yield components.

\footnotetext{
${ }^{1}$ Engenheiro Agrônomo, Doutor, Universidade Camilo Castelo Branco - Campus Fernandópolis - SP. Av. Manoel Marques Rosa $\mathrm{n}^{\circ}$ 1613, Centro, CEP 15 600-000, Fernandópolis, São Paulo, Brasil. e-mail: marcelo.romero@unicastelo.br

${ }^{2}$ Engenheiro Agrí́cola, Doutor, Departamento de Fitossanidade, Engenharia Rural e Solos, Agronomia - UNESP - Ilha Solteira, SP. Av. Brasil Centro 56, CEP 15 850-000, Ilhas Solteira, São Paulo, Brasil. e-mail: ricardo@agr.feis.unesp.br

${ }^{3}$ Engenheiro Agrônomo, Doutor, Departamento de Fitotecnia, Tecnologia de Alimentos e Sócio Economia, UNESP-Ilha Solteira, SP. Av. Brasil Centro 56, CEP 15 850-000, Ilhas Solteira, São Paulo, Brasil. e-mail: arf@agr.feis.unesp.br
} 


\section{INTRODUÇÃO}

O arroz é um importante cereal alimentar utilizado mundialmente e sua procura, cresce devido ao aumento da população e da melhoria no padrão de vida. Grandes avanços têm ocorrido na produção do arroz como resultado da adoção em larga escala de variedades melhoradas, uso adequado de fertilizantes e defensivos, manejo do solo e da água e densidades de semeadura.

Os cultivares de arroz de terras altas lançados atualmente são mais produtivos e respondem ao uso de tecnologia avançada. O maior problema dos cultivares é o aumento do porte da planta, resultando em altos índices de acamamento em alguns deles. Além do acamamento, alguns fatores afetam a produtividade de grãos do arroz de terras altas, como a densidade de semeadura, que influenciam na competição por nutrientes, água e luz segundo Carvalho et al. (2008).

$\mathrm{O}$ uso de reguladores vegetais em culturas anuais visa principalmente à redução do porte da planta e uniformidade de maturação, que podem contribuir para melhorar a produção, e reduzir o acamamento, pela redução do crescimento vegetal. Para Rodrigues et al. (2003), algumas limitações de maximização da produtividade de grãos por acamamento podem ser decorrentes de alta competição das plantas pela luz (alta densidade de plantas), de decréscimo da fotossíntese e de redução na eficiência da colheita.

A adoção de técnicas de cultivo que possibilite melhorar o manejo da cultura do arroz em condições favoráveis ao desenvolvimento das plantas pode ser de suma importância para o aumento da produtividade e qualidade dos grãos obtidos.

O objetivo deste trabalho foi estudar a influência do regulador de crescimento etiltrinexapac em diferentes densidades de semeadura do arroz de terras altas, cultivar BRS Primavera, visando reduzir a altura e diminuir o acamamento das plantas de arroz.

\section{MATERIAL E MÉTODOS}

O experimento foi conduzido no ano de 2008/09, em duas épocas de semeadura, na Fazenda de Ensino e Pesquisa da Universidade Camilo Castelo Branco, Fernandópolis - SP, localizada entre as coordenadas $20^{\circ} 16^{\prime}$ latitude sul e $50^{\circ} 17^{\prime}$ longitude oeste. O clima da região segundo Rolim et al. (2007), e de acordo com a classificação de Koppen, é tropical úmido, Aw, com estação chuvosa no verão e seca no inverno. Segundo a Embrapa (2007), a região é caracterizada por um período de 6 meses do ano com déficit hídrico e temperatura média de 
$23,5^{\circ} \mathrm{C}$. De acordo com Oliveira et al. (1999) os solos foi classificado como Argissolos Vermelhos-Amarelos eutróficos abrúpticos A moderado textura arenosa/média relevo suave ondulado e ondulado. Os valores da analise química foram obtidos de acordo com Raij \& Quaggio, (1983) na camada de 0-20cm, foram: $\mathrm{pH}$ em $\mathrm{CaCl}_{2}=5,0$; M.O. $=14 \mathrm{~g} \mathrm{dm}^{-3}$; $\mathrm{P}($ resina $)=9 \mathrm{mg} \mathrm{dm}^{-3} ; \mathrm{K}=2,2 \mathrm{mmol}_{\mathrm{c}} \mathrm{dm}^{-3} ; \mathrm{Ca}=21 \mathrm{mmol}_{\mathrm{c}} \mathrm{dm}^{-3} ; \mathrm{Mg}=6 \mathrm{mmol}_{\mathrm{c}} \mathrm{dm}^{-3} ; \mathrm{H}+\mathrm{Al}=$ $23 \mathrm{mmol}_{\mathrm{c}} \mathrm{dm}^{-3} ; \mathrm{CTC}=52 \mathrm{mmol}_{\mathrm{c}} \mathrm{dm}^{-3}$ e V\% $=56$. O delineamento experimental utilizado foi de blocos ao acaso, disposto em esquema fatorial 5 x 2, com quatro repetições. Os tratamentos foram constituídos por cinco densidades de semeadura (100, 150, 200, 250 e 300 sementes viáveis $\mathrm{m}^{-2}$ ) combinadas com e sem aplicação de regulador vegetal. A área experimental foi constituída de $450 \mathrm{~m}^{2}$ (29 x 19,8 metros), divididos em 40 parcelas de 10,5 $\mathrm{m}^{2}$, nas dimensões de 5 x 2,1 metros. As parcelas experimentais, foram constituídas de 6 linhas de 5 metros de comprimento, no espaçamento de 0,35 metros entrelinhas, sendo que para área útil das parcelas para fins de colheita e avaliações foram utilizadas as 3 linhas centrais. O regulador vegetal utilizado foi o etil-trinexapac, aplicado no momento da diferenciação do primórdio da panícula na dose $150 \mathrm{~g} \mathrm{ha}^{-1}$ do ingrediente ativo. A aplicação foi realizada na forma de jato dirigido, com pulverizador manual tipo costal, com volume de calda de $250 \mathrm{~L} \mathrm{ha}^{-1}$, aos 40 dias após a emergência das plântulas (DAE) na primeira semeadura e aos 39 DAE na segunda semeadura. As aplicações foram realizadas em horário com ausência ou pouca incidência de vento. O preparo do solo foi realizado com uma aração e duas gradagens niveladoras, para a realização de semeadura. Antes da semeadura foi realizado o tratamento das sementes utilizando-se o produto thiodicarb $\left(300 \mathrm{~g} \mathrm{~L}^{-1}\right)$ na dosagem de $1,5 \mathrm{~L} / 100 \mathrm{~kg}$ de sementes, visando o controle de pragas de solos indesejáveis. A semeadura foi realizada manualmente, utilizando as densidades de 100, 150, 200, 250 e 300 sementes viáveis $\mathrm{m}^{-2}$. A adubação de semeadura foi de $150 \mathrm{~kg} \mathrm{ha}^{-1}$ da fórmula $8-28-16+\mathrm{Zn}$, distribuída manualmente no sulco. A adubação nitrogenada em cobertura foi realizada 30 dias após a emergência das plântulas na primeira e segunda semeadura, aplicando-se $60 \mathrm{~kg} \mathrm{ha}^{-1}$ de nitrogênio na forma de uréia. $\mathrm{O}$ controle das plantas daninhas foi realizado pela aplicação de herbicida herbadox (p.c. 2,5L ha' ${ }^{1}$ ) pré-emergente após a semeadura. O cultivar utilizado foi o BRS Primavera, proveniente do Centro Nacional de Pesquisa de Arroz e Feijão - EMBRAPA. As características fenológicas analisadas foram: altura das plantas; acamamento; número de colmos por metro quadrado; número de panículas por metro quadrado; massa de 100 grãos; produtividade de grãos e rendimento de engenho. Os dados foram submetidos à análise de variância e as médias dos tratamentos comparadas pelo teste $\mathrm{F}$, com $5 \%$ de probabilidade de erro, utilizando-se o programa SISVAR (FERREIRA, 1999). 


\section{RESULTADOS E DISCUSSÃO}

Pela análise dos dados de altura de plantas (Tabela 1), notou-se que a aplicação do regulador proporcionou significativa redução da altura de plantas, sendo 0,36 metros na primeira semeadura e 0,25 metros na segunda. Segundo Davies (1995) a redução da altura de plantas de arroz pode estar associada ao fato de o regulador de crescimento atuar no metabolismo das sínteses de giberelinas das plantas. Para Zagonel et al. (2002), o regulador de crescimento promove uma redução na estrutura das plantas, pela diminuição do comprimento dos entrenós, o que resulta em plantas mais compactas e com melhor direcionamento dos fotoassimilados para a produção de grãos. Em relação à redução da altura das plantas de arroz proporciona melhores índices de colheita e possível redução de acamamento possibilitando melhor manejo da cultura de arroz de terras altas.

Quanto ao acamamento de plantas (Tabela 1), verificou-se que o comportamento foi semelhante, mostrando que a aplicação do regulador de crescimento afeta de forma não significativa está variável (Tabela 5). Considerando as densidades de semeadura de 200, 250 e 300 sementes viáveis $\mathrm{m}^{-2}$, verifica-se que houve redução no índice de acamamento com regulador de crescimento, o mesmo não acontecendo com as densidades de semeaduras menores.

Para densidade de semeadura dentro de regulador (Tabela 5), verificou-se que não houve efeito significativo com aplicação de etil-trinexapac. No tratamento sem regulador as notas de acamamento se ajustaram a uma função linear crescente, indicando que o aumento da densidade de semeadura tende a promover aumento no acamamento, sem aplicação do regulador de crescimento. Crusciol et al. (2000) estudando diferentes densidades de semeadura $\left(100,150\right.$ e 200 sementes viáveis $\mathrm{m}^{-2}$ ) verificaram que todos os tratamentos proporcionaram um índice de acamamento de 15\%, com exceção das densidades de 150 sementes $\mathrm{m}^{-2}$, que apresentou um índice aproximado de $5 \%$, e a densidade de 200 sementes $\mathrm{m}^{-}$ 2 apresentou um índice de $30 \%$ de acamamento. 
Tabela 1. Valores médios para altura de plantas e acamamento, em função do regulador de crescimento e densidade de semeadura em diferentes épocas na cultura do arroz de terras altas. Fernandópolis - SP, 2008/09.

PS (novembro)

SS (dezembro)

\begin{tabular}{cccccc}
\multicolumn{2}{l}{ Tratamentos } & $\begin{array}{c}\text { Altura Planta } \\
(\mathrm{cm})\end{array}$ & $\begin{array}{c}\text { Acamamento }^{(1)} \\
(\text { nota })\end{array}$ & $\begin{array}{c}\text { Altura Planta } \\
(\mathrm{cm})\end{array}$ & $\begin{array}{c}\text { Acamamento } \\
(\text { nota })\end{array}$ \\
\hline \multirow{2}{*}{ RC } & CA & $73 \mathrm{~b}$ & $0,70 \mathrm{~b}$ & $69 \mathrm{~b}$ & 0,70 \\
& SA & $109 \mathrm{a}$ & $1,14 \mathrm{a}$ & $94 \mathrm{a}$ & 0,75 \\
\hline \multirow{2}{*}{ DS } & 100 & 94 & 0,77 & 83 & 0,70 \\
& 150 & 92 & 0,83 & 83 & 0,70 \\
& 200 & 90 & 0,99 & 78 & 0,77 \\
& 250 & 89 & 1,01 & 83 & 0,70 \\
& 300 & 90 & 1,01 & 81 & 0,77 \\
\hline F & RC & $620,66^{* *}$ & $52,51^{* *}$ & $200,01^{* *}$ & $1,93^{\mathrm{ns}}$ \\
& DS & $1,95^{\mathrm{ns}}$ & $2,81^{*}$ & $1,61^{\mathrm{ns}}$ & $0,72^{\mathrm{ns}}$ \\
\hline
\end{tabular}

Médias seguidas de mesma letra, minúscula nas colunas, não diferem estatisticamente entre si pelo teste de Tukey a $5 \%$ de probabilidade. Escala de notas: 0 - sem acamamento; 1 - até $5 \%$ de plantas acamadas; 2 - 5 a $25 \%, 3-25$ a $50 \% ; 4-50$ a $75 \%$ e $5-75$ a $100 \%$ de plantas acamadas. ns - não significativo e $* *, *$ significativo ao nível $1 \%$ e $5 \%$ de probabilidade pelo teste F, respectivamente. RC: Regulador de Crescimento. DS: Densidades de semeadura. CA: Com aplicação. SA: Sem aplicação. CV: Coeficiente de variação. PS: Primeira semeadura. SS: Segunda semeadura. ${ }^{(1)}$ Dados transformados em $(x+0,5){ }^{0,5} \cdot{ }^{(1)} Y=0,0013 x+0,6634$ $\left(r^{2}=0,84\right)$.

Quanto ao número de colmos $\mathrm{m}^{-2}$ (Tabela 2) houve interação da densidade com regulador de crescimento, na primeira semeadura. Verificou-se que os dados se ajustaram a equação linear crescente (Tabela 5), na presença do regulador de crescimento. Para a aplicação do regulador de crescimento dentro de densidade, o número de colmos foi maior no tratamento com regulador nas densidades de 200, 250 e 300 sementes viáveis $\mathrm{m}^{-2}$.

Para a segunda data de semeadura (Tabela 2), verificou-se efeito para regulador e densidade de semeadura. A aplicação de regulador de crescimento proporcionou maior número de colmos $\mathrm{m}^{-2}$. A densidade de semeadura se ajustou a uma equação linear crescente, onde as maiores densidade (200, 250 e 300 sementes viáveis $\mathrm{m}^{-2}$ ) proporcionaram maiores números de colmos por metro quadrado. Os resultados discordam com os obtidos por Crusciol et al. (2000) onde verificaram que houve diferença nas densidades de semeadura para o 
cultivar IAC 201 de 100, 150 e 200 sementes viáveis $\mathrm{m}^{-2}$, sendo a densidade de 100 sementes resultou em maior número de colmos $\mathrm{m}^{-2}$.

Em relação ao número de panículas $\mathrm{m}^{-2}$ (Tabela 2), na primeira semeadura, verificouse efeito apenas do regulador de crescimento, sendo que o tratamento sem aplicação do etiltrinexapac resultou em maior valor em relação ao com aplicação do regulador de crescimento. Esses dados são semelhantes aos obtidos por Alvarez et al. (2007b) os quais verificaram que o número de panículas reduziu com o emprego do etil-trinexapac na aplicação de $200 \mathrm{~g} \mathrm{ha}^{-1}$ de ingrediente ativo em quatro estádios de desenvolvimento das plantas de arroz.

$\mathrm{Na}$ segunda semeadura (Tabela 2) houve efeito do regulador de crescimento e densidade de semeadura. Foi maior o número de panículas para o tratamento com aplicação do regulador em relação ao sem aplicação. A aplicação do regulador de crescimento influenciou de forma negativa para a primeira data e positiva para a segunda, podendo reduzir a produtividade do arroz. Buzetti et al. (2006) mostraram que o regulador de crescimento (cloreto de clormequat) na dose de $1 \mathrm{~L} \mathrm{ha}^{-1}$ e $2 \mathrm{~L} \mathrm{ha}^{-1}$ não influenciou no número de panículas de plantas das cultivares IAC 201 e IAC 202 de arroz de terras altas.

No caso das densidades (Tabela 2) os valores obtidos se ajustaram a equação linear crescente. Verificou-se que quando se aumenta a densidade ocorre aumento do número de panículas, podendo proporcionar um aumento na produtividade de grãos de arroz. O resultado é semelhante ao de Carvalho (2006), que estudando o arroz de terras altas BRSMG Conai em três densidades de semeadura $\left(50,80\right.$ e 110 sementes viáveis $\left.\mathrm{m}^{-2}\right)$, o qual verificou que as maiores densidade de semeadura (80 e 110 sementes viáveis $\mathrm{m}^{-2}$ ) foram as que proporcionaram maiores números de panículas por metro quadrado. Andrade \& Amorim Neto (1996) verificaram aumento da produtividade de grãos e relação direta com o número de panículas por metro quadrado.

Tabela 2. Valores médios do número de colmos por metro quadrado, número de panículas, em função do regulador de crescimento e densidade de semeadura em diferentes épocas na cultura do arroz de terras altas. Fernandópolis - SP, 2008/09.

\begin{tabular}{lccccc}
\hline \multirow{2}{*}{ Tratamentos } & & \multicolumn{2}{c}{ PS (novembro) } & \multicolumn{2}{c}{ SS (dezembro) } \\
\cline { 3 - 6 } & & $\begin{array}{c}\text { Colmos } \\
\mathrm{m}^{-2}\end{array}$ & $\begin{array}{c}\text { Panículas } \\
\mathrm{m}^{-2}\end{array}$ & $\begin{array}{c}\text { Colmos } \\
\mathrm{m}^{-2}\end{array}$ & $\begin{array}{c}\text { Panículas } \\
\mathrm{m}^{-2}\end{array}$ \\
\hline \multirow{2}{*}{$\mathrm{RC}$} & $\mathrm{CA}$ & $350 \mathrm{a}$ & $216 \mathrm{~b}$ & $338 \mathrm{a}$ & $294 \mathrm{a}$ \\
& $\mathrm{SA}$ & $301 \mathrm{~b}$ & $268 \mathrm{a}$ & $276 \mathrm{~b}$ & $227 \mathrm{~b}$ \\
\hline \multirow{2}{*}{$\mathrm{DS}$} & 100 & 280 & 245 & $257^{(1)}$ & $214^{(2)}$ \\
& 150 & 310 & 234 & 305 & 250
\end{tabular}


Tabela 2. Valores médios do número de colmos por metro quadrado, número de panículas, em função do regulador de crescimento e densidade de semeadura em diferentes épocas na cultura do arroz de terras altas. Fernandópolis - SP, 2008/09.

(Conclusão)

\begin{tabular}{cccccc}
200 & 347 & 256 & 327 & 265 \\
& 250 & 339 & 251 & 318 & 281 \\
& 300 & 351 & 225 & 328 & 294 \\
\hline $\mathrm{F}$ & $\mathrm{RC}$ & $16,87^{* *}$ & $23,36^{* *}$ & $35,31^{* *}$ & $39,28^{* *}$ \\
& $\mathrm{DS}$ & $5,14^{* *}$ & $1,13^{\mathrm{ns}}$ & $6,35^{* *}$ & $6,37^{* *}$ \\
& $\mathrm{RCxDS}$ & $3,71^{* *}$ & $0,71^{\mathrm{ns}}$ & $0,65^{\mathrm{ns}}$ & $0,67^{\mathrm{ns}}$ \\
\hline
\end{tabular}

$\begin{array}{llllll}\mathrm{CV} & (\%) & 11,59 & 14,08 & 10,86 & 12,99\end{array}$

Médias seguidas da mesma letra, minúscula nas colunas, não diferem estatisticamente entre si pelo teste de Tukey a $5 \%$ de probabilidade. ns - não significativo e $* * *$, significativo ao nível $1 \%$ e $5 \%$ de probabilidade pelo teste F, respectivamente. RC: Regulador de crescimento. DS: Densidades de semeadura. PS: Primeira semeadura. SS: Segunda semeadura. CA: Com aplicação. SA: Sem aplicação. CV: Coeficiente de variação. ${ }^{(1)} \mathrm{Y}=0,3136 \mathrm{x}+244,49\left(\mathrm{r}^{2}=0,69\right) .{ }^{(2)} \mathrm{Y}=0,3813 \mathrm{x}+184,6\left(\mathrm{r}^{2}=0,95\right)$

Para a massa de 100 grãos (Tabela 3), houve efeito do regulador de crescimento, na primeira semeadura. A massa de 100 grãos foi maior no tratamento com aplicação do regulador, na primeira. Na segunda semeadura, os resultados foram inversos ao da primeira, na segunda data proporcionou maior massa de 100 grãos para o tratamento sem aplicação do etil-trinexapac. Alvarez et al. (2007a) avaliando diferentes doses de cloreto de mepiquat (0, 1000, 2000, 4000 e $\left.8000 \mathrm{mg} \mathrm{L}^{-1}\right)$ o pactobutrazol $\left(0,1000,2000\right.$ e $\left.4000 \mathrm{mg} \mathrm{L}^{-1}\right)$ e o etiltrinexapac $\left(0,2000,4000\right.$ e $\left.8000 \mathrm{mg} \mathrm{L}^{-1}\right)$ para massa de 1000 grãos, foram maiores para o tratamento com etil-trinexapac.

Quanto à produtividade de grãos (Tabela 3), na primeira data de semeadura, houve interação entre regulador de crescimento dentro de densidade (Tabela 5). Verificou-se que não houve diferença para a densidade de 100 sementes viáveis $\mathrm{m}^{-2}$. Nas densidades de 150 a 300 sementes viáveis $\mathrm{m}^{-2}$ a aplicação do regulador proporcionou menores produtividades de grãos em relação ao tratamento sem aplicação do etil-trinexapac. Para o tratamento sem aplicação do regulador de crescimento a densidade de 200 sementes viáveis $\mathrm{m}^{-2}$ proporcionou uma produtividade de grãos de 5\% maior que as outras densidades avaliadas no trabalho. 
Tabela 3. Valores médios da massa de 100 grãos e produtividade de grãos, em função do regulador de crescimento e densidade de semeadura em diferentes épocas na cultura do arroz de terras altas. Fernandópolis - SP, 2008/09.

\begin{tabular}{|c|c|c|c|c|c|}
\hline \multirow{2}{*}{\multicolumn{2}{|c|}{ Tratamentos }} & \multicolumn{2}{|c|}{ PS (novembro) } & \multicolumn{2}{|c|}{ SS (dezembro) } \\
\hline & & $\begin{array}{c}\text { Massa } 100 \text { grãos } \\
(\mathrm{g})\end{array}$ & $\begin{array}{l}\text { Produtividade } \\
\qquad\left(\mathrm{kg} \mathrm{ha}^{-1}\right)\end{array}$ & $\begin{array}{c}\text { Massa } 100 \text { grãos } \\
\text { (g) }\end{array}$ & $\begin{array}{l}\text { Produtividade } \\
\qquad\left(\mathrm{kg} \mathrm{ha}^{-1}\right)\end{array}$ \\
\hline \multirow{2}{*}{$\mathrm{RC}$} & $\mathrm{CA}$ & $2,9 a$ & $2811 b$ & $3,1 b$ & $3015 b$ \\
\hline & SA & $2,8 b$ & $5192 a$ & $3,2 \mathrm{a}$ & $4330 a$ \\
\hline \multirow{5}{*}{ DS } & 100 & 2,8 & 3663 & 3,2 & 3296 \\
\hline & 150 & 2,9 & 3869 & 3,2 & 3785 \\
\hline & 200 & 2,8 & 4497 & 3,1 & 3791 \\
\hline & 250 & 2,8 & 4093 & 3,1 & 4177 \\
\hline & 300 & 2,8 & 3884 & 3,1 & 3313 \\
\hline \multirow{3}{*}{$\mathrm{F}$} & $\mathrm{RC}$ & $7,84 * *$ & $147,62 * *$ & $10,35 * *$ & $30,74 * *$ \\
\hline & DS & $0,38^{\mathrm{ns}}$ & $2,08^{\mathrm{ns}}$ & $0,49^{\mathrm{ns}}$ & $1,96^{\mathrm{ns}}$ \\
\hline & RCxDS & $1,14^{\mathrm{ns}}$ & $5,46^{* *}$ & $1,04^{\mathrm{ns}}$ & $0,48^{\mathrm{ns}}$ \\
\hline $\mathrm{CV}$ & $(\%)$ & 4,73 & 15,49 & 4,87 & 20,43 \\
\hline
\end{tabular}

Médias seguidas da mesma letra, minúscula nas colunas, não diferem estatisticamente entre si pelo teste de Tukey a 5\% de probabilidade. ns - não significativo e **, significativo ao nível $1 \%$ e $5 \%$ de probabilidade pelo teste F, respectivamente. RC: Regulador de Crescimento. DS: Densidade de Semeadura. PS: Primeira semeadura. SS: Segunda semeadura. CA: Com aplicação. SA: Sem aplicação. CV: Coeficiente de variação.

Em relação à densidade de semeadura dentro de regulador de crescimento na produtividade de grãos (Tabela 5), verificou-se para os tratamentos com e sem aplicação do regulador que os dados se ajustaram, a função linear e quadrática, respectivamente. Considerando a produtividade na segunda semeadura (Tabela 3) houve efeito apenas para o regulador de crescimento, proporcionando menor produtividade de grãos do arroz de terras altas. O regulador de crescimento causou redução de $45 \%$ e $30 \%$ na produtividade de grãos de arroz de terras altas na primeira e segunda data respectivamente. Entretanto, Alvarez et al. (2007b) verificaram que em função dos resultados dos componentes da produção, na aplicação de $200 \mathrm{~g} \mathrm{ha}^{-1}$ ingrediente ativo do etil-trinexapac em quatro estádios de desenvolvimento das plantas de arroz para o cultivar BRS Primavera a menor produtividade de grãos foi obtida pela aplicação do etil-trinexapac na dose $150 \mathrm{~g} \mathrm{ha}^{-1}$ do ingrediente ativo. 
Tabela 4. Valores médios do rendimento de beneficiamento, grãos inteiros e quebrados, em função do regulador de crescimento e densidade de semeadura em diferentes épocas na cultura do arroz de terras altas. Fernandópolis - SP, 2008/09.

\begin{tabular}{|c|c|c|c|c|c|c|c|}
\hline \multirow{2}{*}{\multicolumn{2}{|c|}{ Tratamentos }} & \multicolumn{3}{|c|}{ PS (novembro) } & \multicolumn{3}{|c|}{ SS (dezembro) } \\
\hline & & $\begin{array}{c}\text { Rend. } \\
\text { Beneficio } \\
(\%)\end{array}$ & $\begin{array}{c}\text { Grãos } \\
\text { Inteiros } \\
(\%)\end{array}$ & $\begin{array}{c}\text { Grãos } \\
\text { Quebrados } \\
(\%)\end{array}$ & $\begin{array}{c}\text { Rend. } \\
\text { Beneficio } \\
(\%)\end{array}$ & $\begin{array}{c}\text { Grãos } \\
\text { Inteiros } \\
(\%)\end{array}$ & $\begin{array}{c}\text { Grãos } \\
\text { Quebrados } \\
(\%)\end{array}$ \\
\hline & $\mathrm{CA}$ & $76,6 b$ & $62,5 b$ & $14,1 \mathrm{a}$ & $71,7 b$ & $66,0 b$ & $5,7 \mathrm{a}$ \\
\hline $\mathrm{RC}$ & SA & $77,9 \mathrm{a}$ & $66,1 \mathrm{a}$ & $11,8 b$ & $74,6 \mathrm{a}$ & $71,7 \mathrm{a}$ & $3,9 b$ \\
\hline \multirow{5}{*}{ DS } & 100 & $75,2^{(1)}$ & $59,8^{(2)}$ & $15,4^{(3)}$ & 73,4 & 68,9 & 4,5 \\
\hline & 150 & 77,9 & 63,3 & 14,5 & 73,4 & 69,2 & 4,2 \\
\hline & 200 & 77,2 & 65,7 & 11,5 & 73,3 & 68,1 & 5,3 \\
\hline & 250 & 78,1 & 66,1 & 12,1 & 74,7 & 68,4 & 5,2 \\
\hline & 300 & 77,8 & 66,5 & 11,3 & 71,9 & 67,1 & 5,0 \\
\hline \multirow{3}{*}{$\mathrm{F}$} & $\mathrm{RC}$ & $5,16^{* *}$ & $13,18 * *$ & $10,24 * *$ & $21,78 * *$ & $32,31 * *$ & $20,62 * *$ \\
\hline & PP & $3,62 * *$ & $6,61 * *$ & $5,64 * *$ & $1,02^{\mathrm{ns}}$ & $0,74^{\mathrm{ns}}$ & $1,05^{\mathrm{ns}}$ \\
\hline & RCxDS & $0,86^{\mathrm{ns}}$ & $1,21^{\mathrm{ns}}$ & $0,99^{\mathrm{ns}}$ & $0,83^{\mathrm{ns}}$ & $0,63^{\mathrm{ns}}$ & $0,63^{\mathrm{ns}}$ \\
\hline $\mathrm{CV}$ & $(\%)$ & 2,29 & 4,80 & 17,32 & 2,69 & 3,84 & 26,40 \\
\hline
\end{tabular}

Médias seguidas da mesma letra, minúscula nas colunas, não diferem estatisticamente entre si pelo teste de Tukey a $5 \%$ de probabilidade. ns - não significativo e **,* significativo ao nível $1 \%$ e $5 \%$ de probabilidade pelo teste F, respectivamente. RC: Regulador de Crescimento. DS: Densidade de semeadura. PS: Primeira semeadura. SS: Segunda semeadura. CA: Com aplicação. SA: Sem aplicação. CV: Coeficiente de variação. ${ }^{(1)} Y=0,0108 x$ $+75,10\left(\mathrm{r}^{2}=0,52\right) \cdot{ }^{(2)} \mathrm{Y}=0,0325 \mathrm{x}+57,788\left(\mathrm{r}^{2}=0,84\right) \cdot{ }^{(3)} \mathrm{Y}=-0,0217 \mathrm{x}+17,313\left(\mathrm{r}^{2}=0,82\right)$.

Tabela 5. Interação entre densidade de semeadura e regulador de crescimento para acamamento, numero de colmos $/ \mathrm{m}^{2}$ e produtividade na primeira semeadura. Fernandópolis SP, 2008/09.

(Continua)

\begin{tabular}{|c|c|c|c|c|c|c|}
\hline \multirow{3}{*}{$\begin{array}{l}\text { Regulador } \\
\text { Crescimento }\end{array}$} & \multicolumn{5}{|c|}{ Densidade de Semeadura (sementes $\mathrm{m}^{-2}$ ) } & \\
\hline & 100 & 150 & 200 & 250 & 300 & \\
\hline & \multicolumn{5}{|c|}{ Acamamento (notas) (PS) } & \\
\hline $\mathrm{CA}$ & $0,70 \mathrm{a}$ & $0,70 \mathrm{a}$ & $0,70 \mathrm{~b}$ & $0,70 \mathrm{~b}$ & $0,70 b$ & n.s. \\
\hline SA & $0,83 \mathrm{a}$ & $0,96 \mathrm{a}$ & $1,27 \mathrm{a}$ & $1,31 \mathrm{a}$ & $1,31 \mathrm{a}$ & $\mathrm{RL}^{* *}(1)$ \\
\hline \multirow{3}{*}{$\begin{array}{l}\text { Regulador } \\
\text { Crescimento }\end{array}$} & \multicolumn{5}{|c|}{ Densidade de Semeadura (sementes $\mathrm{m}^{-2}$ ) } & \\
\hline & 100 & 150 & 200 & 250 & 300 & \\
\hline & \multicolumn{5}{|c|}{ Colmos $\mathrm{m}^{-2}(\mathrm{PS})$} & \\
\hline
\end{tabular}


Tabela 5. Interação entre densidade de semeadura e regulador de crescimento para acamamento, numero de colmos $/ \mathrm{m}^{2}$ e produtividade na primeira semeadura. Fernandópolis SP, 2008/09.

(Conclusão)

\begin{tabular}{ccccccc}
\hline CA & $268 \mathrm{a}$ & $321 \mathrm{a}$ & $386 \mathrm{a}$ & $367 \mathrm{a}$ & $407 \mathrm{a}$ & $\mathrm{RL}^{* *(2)}$ \\
$\mathrm{SA}$ & $291 \mathrm{a}$ & $298 \mathrm{a}$ & $308 \mathrm{~b}$ & $311 \mathrm{~b}$ & $296 \mathrm{~b}$ & n.s. \\
\hline
\end{tabular}

\begin{tabular}{|c|c|c|c|c|c|c|}
\hline \multirow{2}{*}{$\begin{array}{c}\text { Regulador } \\
\text { Crescimento }\end{array}$} & \multicolumn{5}{|c|}{ Densidade de Semeadura (sementes $\mathrm{m}^{-2}$ ) } & \\
\hline & 100 & 150 & 200 & 250 & 300 & \\
\hline \multicolumn{7}{|c|}{ Produtividade $\left(\mathrm{kg} \mathrm{ha}^{-1}\right)(\mathrm{PS})$} \\
\hline $\mathrm{CA}$ & $3257 \mathrm{a}$ & $2884 b$ & $2960 b$ & $2403 b$ & $2549 b$ & $\mathrm{RL}^{* *(3)}$ \\
\hline SA & $4069 a$ & $4854 \mathrm{a}$ & $6034 a$ & $5784 a$ & $5219 \mathrm{a}$ & $\mathrm{QL}^{* *(4)}$ \\
\hline
\end{tabular}

Médias seguidas da mesma letra na linha, não diferem estatisticamente entre si pelo teste de Tukey a 5\% de probabilidade. ns - não significativo e $* * *$ significativo ao nível $1 \%$ e $5 \%$ de probabilidade pelo teste $\mathrm{F}$, respectivamente. Escala de notas: 0 - sem acamamento; 1 - até $5 \%$ de plantas acamadas; 2 - 5 a $25 \%, 3$ - 25 a $50 \% ; 4-50$ a $75 \%$ e $5-75$ a $100 \%$ de plantas acamadas. PS: Primeira semeadura. CA: Com aplicação. SA: Sem aplicação. Dados transformados em $(x+0,5){ }^{0,5} \cdot{ }^{(1)} Y=0,0026 x+0,6197\left(r^{2}=0,84\right) .{ }^{(2)} Y=0,6456 x+$ $221,02\left(r^{2}=0,84\right) .{ }^{(3)} \mathrm{Y}=-3,795 \mathrm{x}+3570\left(\mathrm{r}^{2}=0,78\right) .{ }^{(4)} \mathrm{Y}=-0,118 \mathrm{x}^{2}+53,657 \mathrm{x}-229,05\left(\mathrm{r}^{2}=0,92\right)$.

Para o rendimento de beneficio (Tabela 4), grãos inteiros e quebrados observaram-se influência negativa do regulador de crescimento na primeira e na segunda data de semeadura. Houve efeito para densidade apenas na primeira data de semeadura. Verificou-se que o tratamento com aplicação do etil-trinexapac diferiu daqueles sem aplicação, apresentando menor valor do rendimento de beneficio e grãos inteiros e, maior valor para grãos quebrados.

Para densidade de semeadura verificou-se que os valores do rendimento de beneficio e grãos inteiros se ajustaram a equação linear crescente, enquanto para os grãos quebrados o ajuste foi para equação linear decrescente. Mariot et al. (2003) relataram que o rendimento de grãos não variou na faixa de densidade de 50 a $200 \mathrm{~kg} \mathrm{ha}^{-1}$ de sementes por metro quadrado, o que mostra a adaptação das plantas de arroz a diferentes densidades semeadura.

Para a segunda semeadura o rendimento de beneficio (Tabela 4), grãos inteiros e quebrados, houve efeito negativo com a aplicação do regulador de crescimento, verificando-se os menores valores para rendimento de beneficio e inteiros e a maior para grãos quebrados para o tratamento com aplicação de regulador em relação aos observados para o tratamento sem aplicação. De maneira geral todos os tratamentos apresentaram boa qualidade industrial.

\section{CONCLUSÃO}

De acordo com os resultados e as condições em que foram realizados os experimentos, conclui-se que: 
A aplicação do etil-trinexapac resultou em plantas com menor altura e acamamento e, reduziu a produtividade de grãos da cultura do arroz. O uso de regulador de crescimento em cultivares com tendência ao acamamento é interessante por possibilitar a colheita mecanizada, o que não é possível em áreas com plantas acamadas.

A utilização do etil-trinexapac no manejo da cultura do arroz de terras altas constitui uma ferramenta importante, mas que ainda influencia nos componentes vegetativos, produtividade e ainda interfere no rendimento industrial do cultivar BRS Primavera .

\section{AGRADECIMENTOS}

Os autores agradecem à Fundação de Apoio à Pesquisa do Estado de São Paulo e a EMBRAPA- Agropecuária Oeste, pelo apoio material.

\section{REFERÊNCIAS}

ALVAREZ, R.C.F.; CRUSCIOL, C.A.C.; RODRIGUES, J. D.; ALVAREZ, A. C.C. Aplicação de reguladores vegetais na cultura de arroz de terras altas. Acta Scientiarum. Agronomy, Maringá, v. 29, n. 2, p. 241-249, 2007 a.

ALVAREZ, R.C.F.; CRUSCIOL, C.A.C.; TRIVELIN, P.C.O.; RODRIGUES, J. D.; ALVAREZ, A.C.C. Influência do etil-trinexapac no acúmulo, na distribuição de nitrogênio $\left({ }_{15} \mathrm{~N}\right)$ e na massa de grãos de arroz de terras altas. Revista Brasileira Ciência do Solo, Viçosa, MG, v.31, p.1487-1496, 2007 b.

ANDRADE, W.E.B.; AMORIM NETTO, S. Influência da adubação nitrogenada sobre o rendimento e outros parâmetros de duas cultivares de arroz irrigado na região norte fluminense. Ciência e Agrotecnologia, Lavras, v.20, p.293-300, 1996.

BUZETTI, S.; BAZANINI, G.C.; FREITAS, J.G.; ANDREOTTI, M.; ARF, O.; SÁ, M.E.; MEIRA, F.A. Resposta de cultivares de arroz a doses de nitrogênio e do regulador de crescimento cloreto de clormequat. Pesquisa Agropecuária Brasileira, Brasília, v.41, n.12, p.1731-1737, 2006.

CARVALHO, J.A. Espaçamento e densidade de semeadura para arroz de terras altas de ciclo superprecoce. Lavras, 2006. 83p. Dissertação (Mestrado em Agronomia) - Lavras: UFLA.

CARVALHO, J.A.; SOARES, A.A.; REIS, M.S. Efeito do espaçamento e densidade de semeadura sobre a produtividade e os componentes de produção da cultivar de arroz BRSMG Conai. Ciência Agrotécnica, Lavras, v.32, n.3, p.785-791, 2008. 
CRUSCIOL, C.A.C.; MACHADO, J.R.; ARF, O.; RODRIGUES, R.A.F. Produtividade do arroz irrigado por aspersão em função do espaçamento e da densidade de semeadura.

Pesquisa Agropecuária Brasileira, Brasília, v.35, n.6, p.1093-1100, 2000.

DAVIES, P.J. Plant hormones: physiology, biochemistry, and molecular biology. 2.ed.

Dordrecht: Kluwer Academic, 1995. 833p.

EMPRESA BRASILEIRA DE PESQUISA AGROPECUÁRIA - Embrapa. Banco de dados climáticos do Brasil. Brasília: Embrapa Monitoramento por Satélites, 2007. Disponível em: http://www.bdclima.cnpm.embrapa.br/. Acesso em: 23 nov. 2008.

FERREIRA, D.F. SISVAR: sistema de análise de variância. versão 4.2. Lavras, Universidade Federal de Lavras, 1999.

MARIOT, C.H.P.; SILVA, P.R.F.; MENEZES, V.G.; TEICHMANN, L.L. Resposta de duas cultivares de arroz irrigado à densidade de semeadura e à adubação nitrogenada. Pesquisa Agropecuária Brasileira, v.38 n.2, p.233-241, 2003.

OLIVEIRA, J.B.; CAMARGO, M.N.; ROSSI, M.; CALDERANO FILHO, B. Mapa pedológico do Estado de São Paulo: legenda expandida. Campinas: Instituto Agronômico/ EMBRAPA Solos. Campinas. 1999. 64p.

RAIJ, B. VAN; QUAGGIO, J.A. Métodos de análises de solo para fins de fertilidade. Campinas: IAC, 1983. 1-31 p. (Boletim técnico, 81).

ROLIM, G.S.; CAMARGO, M.B.P.; LANIA, D.G.; MORAES, J.F.L. Classificação climática de Köppen e de Thornthwaite e sua aplicabilidade na determinação de zonas agroclimáticas para o Estado de São Paulo. Bragantia, Campinas, 66(4): 711-720, 2007.

RODRIGUES O., DIDONET A.D., TEIXEIRA M.C.C, ROMAN E.S. Redutores de crescimento. Embrapa Trigo. Circular Técnica on line. Passo Fundo, RS, 2003.

ZAGONEL, J.; VENERANCIO, WS.; KUNZ, R.P; TANAMAT, H. Doses de nitrogênio e Ciência Rural, v.32, p.25-29, 2002. 